\title{
Mesin Panas Kuantum dengan Sistem Multipartikel dan Multi Keadaan
}

\author{
Heru Sukamto, ${ }^{*}$ Agus Purwanto, dan Bintoro Anang Subagyo ${ }^{\dagger}$ \\ Jurusan Fisika, Fakultas Matematika dan Ilmu Pengetahuan Alam, \\ Institut Teknologi Sepuluh Nopember (ITS), Kampus ITS Sukolilo, Surabaya 60111
}

Intisari

\begin{abstract}
Dalam paper ini, disajikan mesin panas kuantum dengan $m$-fermion dan p-keadaan pada sumur potensial satu dimensi sebagai medium kerja mesin panas kuantum. Siklus Carnot dilakukan dengan dua proses isoenergi dan dua proses iso-entropi, generalisasi keadaan transisi dilakukan setelah proses iso-energi. Parameter ekspansi yang memaksimalkan output daya dihitung untuk setiap konfigurasi keadaan transisi. Didapatkan pula pasangan antara parameter ekspansi dan konfigurasi keadaan transisi yang memaksimalkan daya output.
\end{abstract}

\begin{abstract}
In this paper, we present quantum heat engine with $\mathrm{m}$ fermion in $\mathrm{p}$ state in one-dimensional potential well as working substance. The Carnot circle is considered, with two iso-energetic process and two iso-entropic process. We consider generalize transition state after iso-energetic process. Then we determine an expansion parameter that maximize power output for each configuration transition state. We also calculate a pair of expansion parameter and configuration of transition state that maximize output power
\end{abstract}

KATA KUNCI: quantum heat engine, multiparticle, expansion parameter

\section{PENDAHULUAN}

Penelitian tentang mesin panas kuantum telah berkembang pesat $[1,2]$. Hal dibuktikan dengan publikasi yang cukup banyak akhir-akhir ini. Kajiannya meliputi penggunaan medium kerja sebagai sistem kuantum, mulai dari sumur potensial [3], osilator harmonik [4], hingga spin partikel [5]. Terkait dengan performa mesin, telah dibahas efisiensi mesin panas sistem dua keadaan oleh Bender [1]. Selain itu juga telah dibahas daya output maksimal sistem fermion 2 partikel 3 keadaan oleh Wang [6].

Pada paper ini, dibahas mesin panas quantum dengan sistem $\mathrm{p}$ keadaan dan $\mathrm{m}$ partikel. Dapat dikatakan, ini merupakan lanjutan dari pekerjaan Wang [6]. Pemilihan sistem multi keadaan, akan diperoleh lebih dari satu alternatif energi sistem tereksitasi. Kemudian dibandingkan performa mesin panas pada siklus Carnot terhadap pemilihan energi tereksitasi. Setelah itu, ditentukan parameter ekspansi (r) yang menghasilkan performa maksimum untuk setiap energi tereksitasi. Diketahui bahwa setiap energi tereksitasi yang dipilih, akan menghasilkan daya keluaran yang bernilai maksimum pada nilai parameter ekspansi tertentu. Selanjutnya akan ditentukan pasangan energi tereksitasi dan parameter ekspansi yang menghasilkan daya output yang maksimum.

Paper ini disusun sebagai berikut, pertama dibahas Carnot Cycle dengan proses isoenergetik awal dari keadaan dasar ke

\footnotetext{
*E-MAIL: herusukamto@physics.its.ac.id

†E-MAIL: b_anang@physics.its.ac.id
}

keadaan eksitasi pertama, kemudian digeneraliasi keadaan eksitasi dan ditentukan range parameter ekspansi tiap keadaan eksitasi yang dipilih. Selain itu ditentukan keadaan eksitasi yang tepat, agar diperoleh daya output yang maksimum.

\section{MESIN PANAS KUANTUM MULTI KEADAAN}

Ide kunci dari termodinamika kuantum adalah menganalogikan hukum pertama termodinamika

$$
d E=d Q+d W
$$

dengan diferensiasi energi total sistem kuantum sebagai berikut

$$
d E=\sum_{n} p_{n} d \epsilon_{n}+\sum_{n} \epsilon_{n} d p_{n}
$$

sehingga diperoleh relasi

$$
\begin{aligned}
d Q & =\sum_{n} \epsilon_{n} d p_{n} \\
d W & =\sum_{n} p_{n} d \epsilon_{n}
\end{aligned}
$$

Sedangkan gaya pada dinding diberikan oleh $\mathrm{F}=-\frac{d E}{d L}$. Diasumsikan dinding potensial bergerak dengan sangat lambat namun dengan kecepatan konstan selama siklus Carnot.

Diperkenalkan m fermion berada pada kotak potensial 1D. Karena memenuhi prinsip larangan Pauli, energi keadaan 

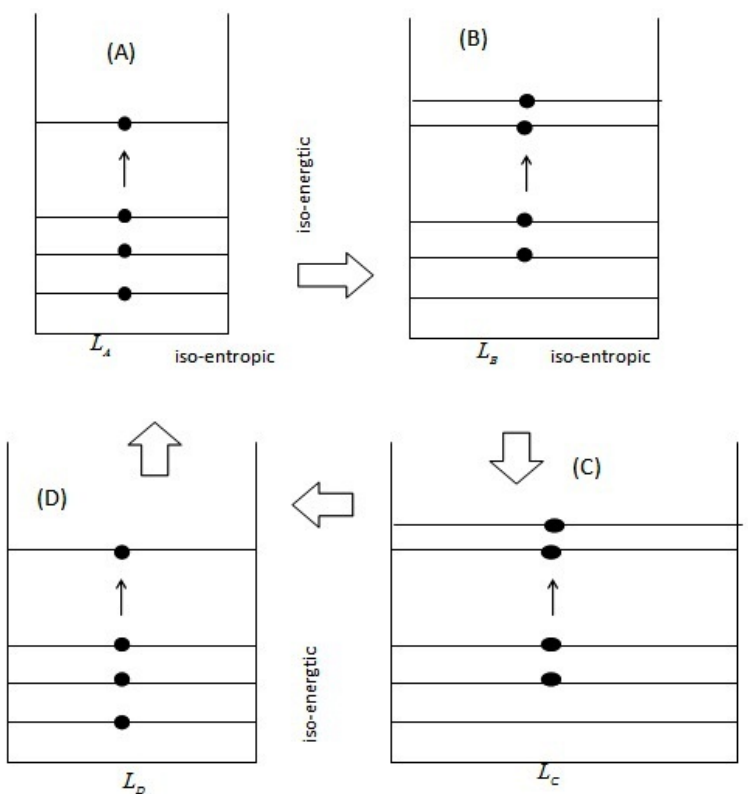

Gambar 1: Grafik kerja siklus Carnot untuk system multi keadaan dan multi partikel.

eigen setiap partikel pada kotak potensial diberikan oleh

$$
E_{A}=\frac{\hbar^{2} \pi^{2}}{2 M L_{A}^{2}}\left[\frac{1}{6} m(m+1)(2 m+1)\right]
$$

dengan $\mathrm{L}_{A}$ merupakan lebar sumur potensial mula-mula. Dipilih keadaan eksitasi pertama pasca proses iso-energi yang pertama seperti pada Gambar 1.

$$
E_{B}=\frac{\hbar^{2} \pi^{2}}{2 M L_{B}^{2}}\left[\frac{1}{6} m(m+1)(2 m+1)+m(m+2)\right]
$$

Selama berekspansi dari keadaan A ke keadaan B, energi total berubah sebagai fungsi panjang $\mathrm{L}$ sebagai berikut

$$
E_{H}=\frac{\hbar^{2} \pi^{2}}{2 M L^{2}} \sum_{n=1}^{m} \sum_{k=1}^{p} k^{2}\left|a_{n k}\right|^{2}
$$

dengan $a_{n k}$ merupakan amplitudo probabilitas partikel ke-n pada level energi k. Selama proses energetik pertama, nilai energi total sama. Gaya pada dinding potensial selama proses iso-energetik dapat ditentukan sebagai berikut

$$
F_{A B}=\frac{\hbar^{2} \pi^{2}}{M L^{3}} \sum_{n=1}^{m} \sum_{k=1}^{p} k^{2}\left|a_{n k}\right|^{2}
$$

dengan Pers. (5) dan (7), diperoleh relasi

$$
L^{2}=L_{1}^{2} \frac{1}{\frac{1}{6} m(m+1)(2 m+1)} \sum_{n=1}^{m} \sum_{k=1}^{p} k^{2}\left|a_{n k}\right|^{2}
$$

sehingga Pers. (8) dapat dituliskan

$$
F_{A B}(L)=\frac{\hbar^{2} \pi^{2}}{M L_{1}^{3} L}\left[\frac{1}{6} m(m+1)(2 m+1)\right]
$$

Analog dengan termodinamika klasik, selama proses isoenergetik, besarnya kalor yang masuk akan diubah semuanya menjadi kerja pada sistem. Dengan demikian kalor yang masuk dapat dihitung sebagai berikut

$$
\begin{aligned}
Q_{H} & =\int_{L_{A}}^{L_{B}} F_{A B}(L) d L \\
& =\frac{\hbar^{2} \pi^{2}}{M L_{1}^{2}}\left[\frac{1}{6} m(m+1)(2 m+1)\right] \ln \left(\frac{L_{B}}{L_{A}}\right)
\end{aligned}
$$

Berikutnya adalah proses iso-entropik B ke C. Selama proses iso-entropik, tidak ada kalor yang masuk. Sehingga perubahan energi total melalui ekspansi jarak L akan berubah menjadi kerja pada sistem, dengan demikian selama ekspansi $\mathrm{L}_{C} \rightarrow \mathrm{L}_{B}$, kerja yang dilakukan pada sistem diberikan sebagai berikut

$$
\begin{aligned}
W_{B C}= & -\Delta E_{B C}=E_{B}-E_{C} \\
= & \frac{\hbar^{2} \pi^{2}}{2 M}\left(\frac{1}{L_{B}^{2}}-\frac{1}{L_{C}^{2}}\right) \\
& \times\left[\frac{1}{6} m(m+1)(2 m+1)+m(m+2)\right]
\end{aligned}
$$

Cara yang sama berlaku pada proses A ke B, kalor yang keluar dari sistem selama proses iso-energi $\mathrm{C}$ ke $\mathrm{D}$ diberikan oleh

$$
\begin{aligned}
Q_{C D}= & \int_{L_{C}}^{L_{D}} F_{D C} d L \\
= & \frac{\hbar^{2} \pi^{2}}{M L_{C}^{2}}\left[\frac{1}{6} m(m+1)(2 m+1)+m(m+2)\right] \\
& \times \ln \left(\frac{L_{D}}{L_{C}}\right)
\end{aligned}
$$

Analog dengan proses B ke C, kerja selama proses isoentropi D ke A diberikan oleh

$$
\begin{aligned}
W_{D A}= & -\Delta E_{D A} \\
= & E_{A}-E_{D} \\
= & \frac{\hbar^{2} \pi^{2}}{2 M}\left(\frac{1}{L_{A}^{2}}-\frac{1}{L_{D}^{2}}\right) \\
& \times\left[\frac{1}{6} m(m+1)(2 m+1)+m(m+2)\right]
\end{aligned}
$$

Dengan menggunakan relasi selama proses iso-energi $\mathrm{AB}$ dan CD

$$
\begin{aligned}
& L_{B}^{2}=L_{A}^{2} \frac{\frac{1}{6} m(m+1)(2 m+1)+m(m+2)}{\frac{1}{6} m(m+1)(2 m+1)} \\
& L_{D}^{2}=L_{C}^{2} \frac{\frac{1}{6} m(m+1)(2 m+1)}{\frac{1}{6} m(m+1)(2 m+1)+m(m+2)}
\end{aligned}
$$


Kerja selama satu siklus dapat diberikan oleh

$$
\begin{aligned}
W= & Q_{H}-Q_{C} \\
= & \frac{\hbar^{2} \pi^{2}}{2 M}\left[\frac{\frac{1}{6} m(m+1)(2 m+1)}{L_{A}^{2}}-\frac{\frac{1}{6} m(m+1)(2 m+1)+m(m+2)}{L_{C}^{2}}\right] \\
& \times \ln \left(\frac{\frac{1}{6} m(m+1)(2 m+1)+m(m+2)}{\frac{1}{6} m(m+1)(2 m+1)}\right)
\end{aligned}
$$

Didefinisikan parameter ekspansi $\mathrm{r}=\mathrm{L}_{C} / \mathrm{L}_{A}$, sehingga nilai efisiensi mesin dapat dinyatakan dengan

$$
\eta=1-\frac{1}{r^{2}}\left[\frac{\frac{1}{6} m(m+1)(2 m+1)+m(m+2)}{\frac{1}{6} m(m+1)(2 m+1)}\right]
$$

Agar nilai efisiensi tidak nol, maka parameter ekspansi harus memenuhi ketidaksamaan berikut

$$
r>\sqrt{\frac{\frac{1}{6} m(m+1)(2 m+1)+m(m+2)}{\frac{1}{6} m(m+1)(2 m+1)}}
$$

\section{OPTIMASI MESIN DAN DAYA KELUARAN}

Dipilih keadaan eksitasi pertama untuk keadaan transisi proses iso-energi. Namun, secara umum bisa juga dipilih keadaan eksitasi yang lain sebagai berikut

$$
E_{B}=\frac{\hbar^{2} \pi^{2}}{2 M L_{B}^{2}} P_{s}(m, p)
$$

Jika sistem memiliki $\mathrm{p}$ keadaan, maka akan terdapat $p ! / m !(p-m)$ ! alternatif keadaan eksitasi. Didefisikan $P_{s}(m, p)$ sebagai konfigurasi energi sistem, dengan indeks berjalan dari 1 hingga $p ! / m !(p-m)$ !. Sedangkan $P_{s}(m, p)$ memiliki interval dari energi total terendah hingga tertinggi sebagai berikut

$$
\begin{aligned}
\frac{1}{6} m(m+1)(2 m+1)< & P_{s}(m, p) \leq \frac{1}{6} m(m+1)(2 m+1) \\
& +(p-m) m(m+1) \\
& +(p-m)^{2} m
\end{aligned}
$$

dengan demikian, untuk pemilihan keadaan eksitasi de- ngan konfigurasi $P_{s}(m, p)$ diperoleh efisiensi mesin

$$
\eta=1-\frac{1}{r^{2}} \frac{P_{s}(m, p)}{\frac{1}{6} m(m+1)(2 m+1)}
$$

dari persamaan di atas, tampak bahwa semakin besar energi keadaan tereksitasi yang dipilih,untuk parameter ekspansi yang sama, akan diperoleh efisiensi mesin yang semakin kecil. Oleh karena itu, perlu diimbangi dengan pemilihan nilai parameter ekspansi.

Selanjutnya akan ditentukan relasi antara pemilihan keadaan tereksitasi dengan daya keluaran mesin. Pertama akan ditentukan terlebih dahulu total pergeseran dinding

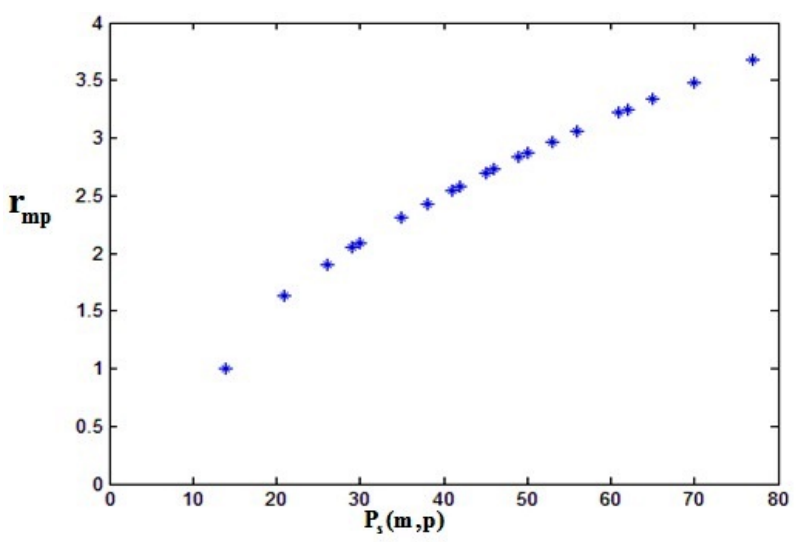

Gambar 2: Konfigurasi keadaan eksitasi versus parameter ekspansi yang memaksimalkan daya keluarankasus 3 fermion, 6 keadaan.

sumur potensial. Selama siklus Carnot, total pergeseran dinding potensial adalah

$$
\begin{aligned}
L_{\circ}= & \left.\left.\left(L_{B}-L_{A}\right)+\right) L_{C}-L_{B}\right) \\
& +\left(L_{C}-L_{D}\right)+\left(L_{D}-L_{A}\right) \\
= & 2\left(L_{C}-L_{A}\right)
\end{aligned}
$$

Jika dinding potensial bergerak dengan kecepatan rerata $\vec{v}$, maka waktu rerata selama satu siklus adalah

$$
\tau=\frac{L_{\circ}}{\vec{v}}=\frac{2\left(L_{C}-L_{A}\right.}{\vec{v}}
$$

dengan demikian, daya keluaran pada satu siklus Carnot dengan menggunakan Pers. (17) dan (23) adalah

$$
\begin{aligned}
P= & \frac{\hbar^{2} \pi^{2} \vec{v}}{4 M L_{1}^{3}}\left[\frac{\frac{1}{6} m(m+1)(2 m+1)}{r-1}-\frac{P_{s}(m, p)}{r^{2}(r-1)}\right] \\
& \times \ln \left(\frac{P_{s}(m, p)}{\frac{1}{6} m(m+1)(2 m+1)}\right)
\end{aligned}
$$

dengan mendefinisikan $\mathrm{A}=\hbar^{2} \pi^{2} \vec{v} / M L_{1}^{3}$, diperoleh bentuk daya keluaran tak berdimensi sebagai berikut

$$
\frac{P}{A}=\frac{1}{4}\left[\frac{14}{r-1}-\frac{P_{s}(m, p)}{r^{2}(r-1)}\right] \ln \left(\frac{P_{s}(m, p)}{14}\right)
$$

Daya keluaran maksimum dapat ditentukan dengan 


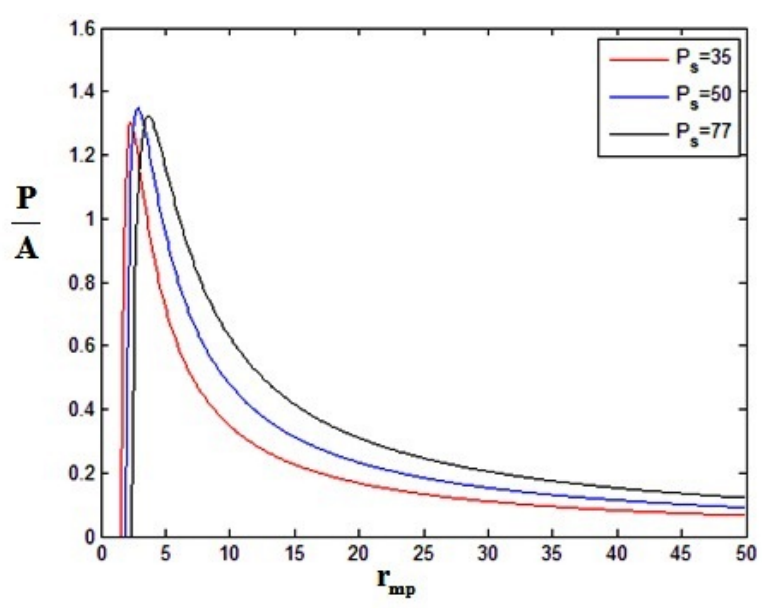

(a)

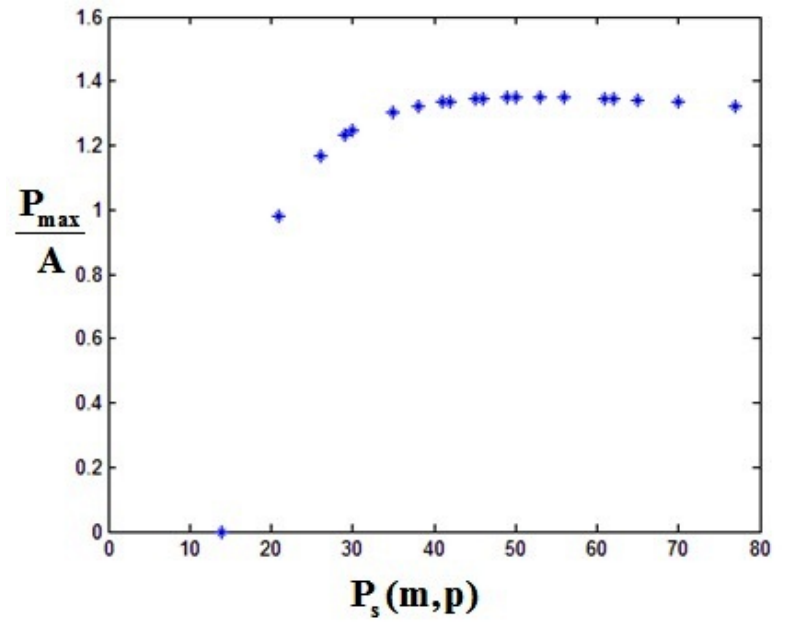

(b)

Gambar 3: (a). Parameter ekspansi versus daya keluaran kasus 3 fermion, 6 keadaan, (b). Konfigurasi energi dan daya maksimum yang dihasilkan.

$\frac{\partial P}{\partial r}_{r=r_{n p}}=0$, sehingga diperoleh relasi

$$
\begin{aligned}
r_{m p}^{3}- & \frac{3 P_{s}(m, p)}{\frac{1}{6} m(m+1)(2 m+1)} r_{m p} \\
& +\frac{2 P_{s}(m, p)}{\frac{1}{6} m(m+1)(2 m+1)}=0
\end{aligned}
$$

Gambar 2 menampilkan relasi antara parameter ekspansi r yang menghasilkan dayakeluaran maksimum dengan konfigurasi $\mathrm{P}_{S}(m, p)$ yang dipilih. Diambil kasus $\mathrm{p}=6$ dan $\mathrm{m}=3$, sehingga terdapat 19 alternatif keadaan tereksitasi. Dari Gambar 2, tampak bahwa semakin tinggi keadaan eksitasi yang dipilih maka semakin besar parameter ekspansi yang memaksimalkan daya keluaran.

Pada Gambar 3(a), ditampilkan daya keluaran untuk beberapa keadaan transisi yang mungkin. Tampak terdapat sedikit variasi daya output maksimum untuk setiap pemilihan konfigurasi energi. Dengan demikian, pemilihan keadaan tereksitasi menjadi penting guna memaksimalkan dayakeluaran. Yang kemudian ditentukan relasi antara konfigurasi energi dan maksimum daya keluaran seperti pada Gambar 3(b).
Tampak bahwa keadaan eksitasi yang memaksimalkan daya output bukanlah energi terendah maupun yang tertinggi. Pada kasus 3 fermion dan 6 keadaan, diperoleh konfigurasi yang memaksimalkan daya keluaran adalah 56. Dengan demikian, untuk menghasilkan daya keluaran maksimum, dipilih keadaan eksitasi dengan konfigurasi 56 dan parameter ekspansi 3,06418.

\section{SIMPULAN}

Berdasarkan perhitungan secara analitik, diperoleh bahwa untuk sistem multi partikel dan multi keadaan, pemilihan keadaan tereksitasi pasca proses iso-energi dan parameter ekspansi berpengaruh pada nilai efisiensi dan daya keluaran mesin. Untuk setiap sistem dengan jumlah level keadaandan jumlah fermion, terdapat pasangan konfigurasi energi dan parameter ekspansi yang memaksimalkan daya keluaran. Pada kasus 3 fermion dan 6 keadaan, konfigurasi energi dan parameter ekspansinya adalah 56 dan 3,06418.
[1] B.C.M. Bender, D.C. Brody, Meister, J. Phys. A, 33, 4427-4436 (2000).

[2] E. Latifah, and Purwanto, J. Mod. Phys, 2, 1366-1372 (2011).

[3] H.T. Quan, et al., Phys. Rev. E, 76, 1-18 (2007).
[4] B. Lin, and J. Chen, Phys. Rev. E, 67, 1-8 (2003).

[5] J. Chen, and B. Hua, Phy. Rev. E, 65, 1-8 (2002).

[6] J. Wang, and J. He, Journal of Applied Physics, 111, 1-7 (2012). 